\title{
EVALUACIÓN DE CUATRO DISTANCIAS DE SIEMBRA Y DOS DE DESHIJA EN PALMITO DE PEJIBAYE SIN ESPINAS
}

\author{
Antonio Bogantes Arias ${ }^{1}$
}

\begin{abstract}
RESUMEN
Evaluación de cuatro distancias de siembra y dos de deshija en palmito de pejibaye sin espinas. Con el objetivo de comparar sistemas de producción de palmito manejados a baja y alta densidad de siembra se hizo este estudio desde enero del 2009 a diciembre del 2011 en una parcela de pejibaye sin espinas de la variedad Diamantes 10 con 11 años de edad. La parcela estaba ubicada en la Estación Experimental Los Diamantes del Instituto Nacional de Innovación y Transferencia en Tecnología Agropecuaria (INTA), situada en Pococí, provincia de Limón. Los tratamientos evaluados fueron la combinación de cuatro distancias de siembra con dos técnicas de manejo de cepa, para un total de ocho combinaciones factoriales. Para la producción de palmitos se analizó la cosecha desde su inicio (año 2001), la cual fue superior en la distancia $0,25 \mathrm{~m}$ entre plantas (20 000 plantas ha-1) con una producción promedio de 15055 palmitos ha- $^{-1}$ y descendió conforme aumentó la distancia con un promedio de 9273 palmitos en la distancia de $1 \mathrm{~m}$ entre plantas. Se observó que independiente de la densidad, por cada $100 \mathrm{~kg}$ de biomasa fresca cortados, $80 \mathrm{~kg}$ se incorporan al sistema (suelo) y $20 \mathrm{~kg}$ se van en el palmito extraído. En las parcelas con plantas sembradas a $1 \mathrm{~m}$ entre sí, las cepas midieron $0,55 \times 0,42 \times 0,20 \mathrm{~m}$ en su relación de largo, ancho y altura respectivamente; mientras que en las parcelas con plantas de nueve años sembradas a 0,25 m entre sí, la cepa ya se había convertido en un surco. En cada cepa el número de hijos disminuyó conforme se redujo la distancia entre plantas. Se identificaron un total de 23 especies de arvenses y se evidenciaron cambios en la diversidad de las especies dominantes con respecto a otras épocas de muestreo. Se determinó estabilidad en el suelo de las cantidades de N-P-K medidas al final del estudio y comparadas con la información de once años atrás. Las cantidades de unidades formadoras de colonias de hongos y bacterias, fueron muy bajas en las parcelas a 0,25 m mientras que las cantidades de UFC de actinos en el suelo de las mismas parcelas fueron mucho más altas. Se describieron los hongos Phytophthora sp. y Fusarium sp., los cuales son patogénicos al cultivo y otros seis hongos no patogénicos a las plantas de palmito. La cantidad de lombrices encontradas fue superior en el suelo de las parcelas con plantas a 0,25 $\mathrm{m}$ y disminuyó conforme aumentó la distancia entre plantas.
\end{abstract}

Palabras clave: Bactris gasipaes K., densidad de siembra, cosecha.

\section{INTRODUCCIÓN}

El palmito de pejibaye es una actividad que genera más de 20 millones de dólares por año en exportaciones. Se estima que en el país existen aproximadamente 7500 ha (SEPSA 2006), con más de 1000 productores distribuidos y organizados en casi todo el país.

En la década de los años 90 existían plantaciones con rendimientos alrededor de
20000 palmitos ha-1 año-1 $^{-1}$ y se estimaba que el promedio nacional era alrededor de 10000 unidades ha ${ }^{-1}$. A partir del segundo semestre de 1997, la sobreproducción y la competencia por las exportaciones en el exterior influyeron en la caída de los precios al productor, lo cual, repercutió negativamente en el manejo y en el rendimiento. En la actualidad, aunque el precio mejoró, aún no se han logrado los rendimientos anteriores, salvo algunas excepciones.

\footnotetext{
${ }^{1}$ Instituto Nacional de Innovación y Transferencia en Tecnología Agropecuaria, INTA. Costa Rica. abogantes@inta.go.cr.
} 
Uno de los aspectos técnicos relacionados con el bajo rendimiento actual, es la escasa población de cepas por área, ya sea por muerte o por densidad de siembra. Aunque los precios por unidad o candela sean buenos, los bajos rendimientos ponen en desventaja al productor ante el alza diaria en los costos de los insumos y mano de obra.

Se han hecho varios estudios sobre distancias de siembra en palmito de pejibaye con espinas (Zamora 1984, Chalá 1991, Vargas 1994, 2000, Mora 1999). Las distancias se fueron modificando con el tiempo hasta llegar a $2 \times 1 \mathrm{~m}$ con una densidad de 5000 plantas ha-1, que se convirtió en la densidad estándar en el pejibaye con espinas por mucho tiempo (Bogantes 2010).

Mora (1989), señala que existen factores que obligan a variar las distancias y cita la variedad como un factor que empieza a jugar un papel importante en las densidades. La ausencia de espinas afecta en la decisión por seleccionar una u otra distancia.

La densidad de siembra también influye en la práctica de deshija, sobre todo, en el palmito con espinas. En un sistema de manejo a libre crecimiento, la cepa llega a ser improductiva porque el aumento en el número de tallos reduce el crecimiento individual, esto justifica la deshija. Los brotes o "hijos" de la cepa o "araña", se pueden clasificar de acuerdo con su posición en brote de cima, aquel situado sobre la araña cuyas raíces no hacen contacto con el suelo por lo cual deben ser podados para evitar que la cepa se encime y el brote periférico, situado en la periferia de la araña, en contacto con el suelo, son los que añaden volumen a la raíz y por último, el brote radical, que surge de la raíz (Mora 1999).

El potencial de producción en palmito sin espinas es alto (Mora 1999). A nivel experimental se han obtenido altos rendimientos en producción de palmitos sobre todo con la nueva variedad de pejibaye sin espinas conocida como Diamantes 10 (Arroyo y Mora 2002; Bogantes et al. 2004, Bogantes
2007, Chaimsohn et al. 2007). Aunque la adopción para la siembra a alta densidad es lenta; ya se observan algunas iniciativas por romper la barrera de las 5000 cepas por hectárea con algunos intentos por sembrar a $2,0 \mathrm{~m}$ entre hilera por $0,70 \mathrm{~m}$ entre planta y a 2,0 m por 0,50 m (10 000 plantas ha-1).

El objetivo de este trabajo fue comparar sistemas de producción de palmito sin espinas, manejados a baja y alta densidad en una siembra de 11 años de edad.

\section{MATERIALES Y MÉTODOS}

\section{Área y época del estudio}

El estudio se llevó a cabo desde enero del año 2009 a diciembre del 2011 en una parcela de pejibaye sin espinas de la variedad Diamantes 10 , sembrada en marzo del año 2000 en la Estación Experimental Los Diamantes del Ministerio de Agricultura y Ganadería, ubicada en Guápiles, cantón Pococí, provincia de Limón; a una altitud de $249 \mathrm{~m}$, con una temperatura mínima promedio de $24^{\circ} \mathrm{C}$ y una máxima promedio de $29^{\circ} \mathrm{C}$. La precipitación promedio anual es de $4500 \mathrm{~mm}$. La fertilización y el manejo de malezas se hicieron siguiendo las instrucciones indicadas en el manual de recomendaciones del cultivo (Bogantes 2010).

\section{Tratamientos}

Los tratamientos evaluados fueron la combinación de cuatro distancias de siembra con dos técnicas de manejo de cepa para un total de ocho combinaciones factoriales (Cuadro 1).

La técnica con deshija consistió en eliminar durante los primeros tres años de edad los brotes de encima, hijos muy cercanos entre sí o con poco vigor y pobre sanidad. Esta práctica se hizo dos veces por año. En la técnica sin deshija no se removió ningún brote. Se hizo una limpieza general de la cepa en ambas estrategias, eliminando hojarasca u hojas viejas dos veces por año. En ninguno de los 
tratamientos se hizo resiembra después de las ocho semanas, para observar la dinámica en el crecimiento de las cepas.

\section{Diseño experimental}

Se usó un diseño de parcelas divididas, distribuidas en cinco bloques al azar. La estrategia de manejo de cepa se asignó a la parcela grande y las distancias de siembra entre plantas a la pequeña, para un total de 40 parcelas. Cada parcela pequeña midió $64 \mathrm{~m}^{2}$ y se usó un área útil de $48 \mathrm{~m}^{2}$; el área experimental total fue de $3456 \mathrm{~m}^{2}$.
Las variables evaluadas fueron:

Número de palmitos. Se midieron las cosechas del 2009 al 2010 y se analizaron junto con la producción de palmito desde el inicio de cosecha (2001). Se cortaron los tallos (unidades de palmito) con un promedio de $9 \mathrm{~cm}$ de grosor, medidos en la base a $10 \mathrm{~cm}$ del suelo. El palmito se dejó con una vaina (cáscara) y con una longitud de $75 \mathrm{~cm}$. Se contaron las tres filas centrales de cada parcela.

Cuadro 1. Arreglo de distancias de siembra y técnicas de manejo de cepa. Guápiles, Limón, Costa Rica. Período de manejo 2000-2011.

\begin{tabular}{|c|c|c|c|}
\hline $\begin{array}{c}\text { Distancia hilera } \\
(\mathrm{m})\end{array}$ & $\begin{array}{c}\text { Distancia planta } \\
(\mathrm{m})\end{array}$ & $\begin{array}{c}\text { Densidad } \\
\left(\text { plantas ha }^{-1}\right)\end{array}$ & Manejo de cepa \\
\hline 2,00 & 0,25 & 20000 & Sin deshija \\
2,00 & 0,50 & 10000 & Sin deshija \\
2,00 & 0,75 & 6666 & Sin deshija \\
2,00 & 1,00 & 5000 & Sin deshija \\
\hline 2,00 & 0,25 & 20000 & Con deshija \\
2,00 & 0,50 & 10000 & Con deshija \\
2,00 & 0,75 & 6666 & Con deshija \\
2,00 & 1,00 & 5000 & Con deshija \\
\hline
\end{tabular}

Rendimiento de palmito foliar y palmito caulinar en gramos. Se cortaron tres plantas por parcela en octubre del 2009 y se midió la longitud de la candela, el número de trozos y el peso (g) del palmito foliar y caulinar (cabeza). Peso en kilogramos de palmito foliar y el número de cajas estándar por parcela. El peso por parcela es el producto del número de palmitos por su peso fresco; mientras que el número de cajas estándar es ese cociente dividido entre 5,28 kg que es el peso del palmito drenado contenido en una caja estándar para exportación. Estas variables se estimaron en palmito fresco, el cual se cortó en plantas con no menos de $9 \mathrm{~cm}$ en la base y con un palmito de $75 \mathrm{~cm}$ (promedio) de longitud, con el fin de corroborar el rendimiento potencial de palmito foliar y caulinar en esta variedad Diamantes 10.
Biomasa de planta y palmito. Se cortaron tres plantas por parcela en octubre del 2009 y se midió su altura $(\mathrm{cm})$, grosor $(\mathrm{cm})$, peso total (kg) de la planta entera, así como el peso (kg) del palmito a una cáscara. Se calculó a) Porcentaje $(\%)$ de extracción= (Peso del palmito a una cáscara/peso total de la planta) x 100 , b) Peso fresco (kg/ha) anual de la biomasa incorporada $=($ Peso total de la planta peso del palmito a una cáscara) x el número promedio de palmitos ha-1 cosechados.

Estudio de cepa. Se contó para cada distancia el número de cepas (mayo 2009). Además, se midió el largo, el ancho y la altura en tres cepas por parcela; así como, el número de estípites (tallos) su altura y grosor en tres plantas por parcela (agosto 2009). En el caso de las cepas a 0,25 m, por la unión entre ellas y su forma de surco, se delimitó el ancho y la altura en una longitud predefinida de $50 \mathrm{~cm}$. 
Cobertura de arvenses (malezas). Se estimó el porcentaje de cobertura de malezas total (octubre 2009) y por especie (mayo del 2011), según la distancia de siembra. Consistió en una estimación de área por parcela con el uso de un marco 0,50 x 0,50 m lanzado al azar en la entrecalle.

Estudios de suelo. Se hizo un muestreo compuesto por las cinco repeticiones para cada distancia (octubre del 2009) para la medición de nutrimentos químicos, y unidades formadoras de colonias (UFC) de microorganismos del suelo (hongos, bacterias y actinos). Para el conteo de lombrices se hizo una muestra por repetición (cuatro submuestras) o sea cinco por distancia. Ambos muestreos se hicieron en el centro de la entrecalle con un palín de $20 \times 20 \mathrm{~cm}$. Las muestras fueron procesadas en el laboratorio de suelos del INTA-MAG. El conteo de las lombrices se hizo en el centro de la entrecalle con una muestra tomada con palín $(20 \times 20 \times 40 \mathrm{~cm})$ o sea $0,016 \mathrm{~m}^{3}$ para un total de 16 litros de suelo.

El análisis estadístico de las variables se hizo con el programa SAS (López y López 1995). Se hizo análisis de varianza, y separación de medias. Se correlacionó la altura de la planta y el grosor del tallo a la cosecha. En las mediciones de nutrimentos y UFC de microorganismos no se hizo ANDEVA, sus promedios se utilizaron para referenciar posibles cambios con respecto a los promedios de otros muestreos realizados al inicio del experimento (2000) y a los 13 meses después de la siembra (mds).

\section{RESULTADOS Y DISCUSIÓN}

No hubo diferencias en el sistema de deshija (con y sin) para las variables de arvenses, producción de palmitos y rendimiento industrial, evaluadas en el período de 2009 al 2011, similar a lo encontrado en los años en los cuales se le dio énfasis a esa práctica de deshija (2001-2003) (Bogantes et al. 2003, 2004).

\section{Producción de palmitos}

La producción promedio de palmitos para el período 2001-2010 fue diferente entre distancias de siembra $(p=0,0001)$. La producción media fue máxima en el tratamiento con la distancia de $0,25 \mathrm{~m}$ entre planta y descendió conforme aumentó la distancia entre planta, con un comportamiento curvilíneo que se estabilizó cuando la distancia fue de 1,0 m entre planta (Figura 1). Dicho comportamiento ya se había manifestado con esa tendencia en el 2001 (Bogantes et al. 2004) y entre 2002 y el 2004 (Bogantes 2007).

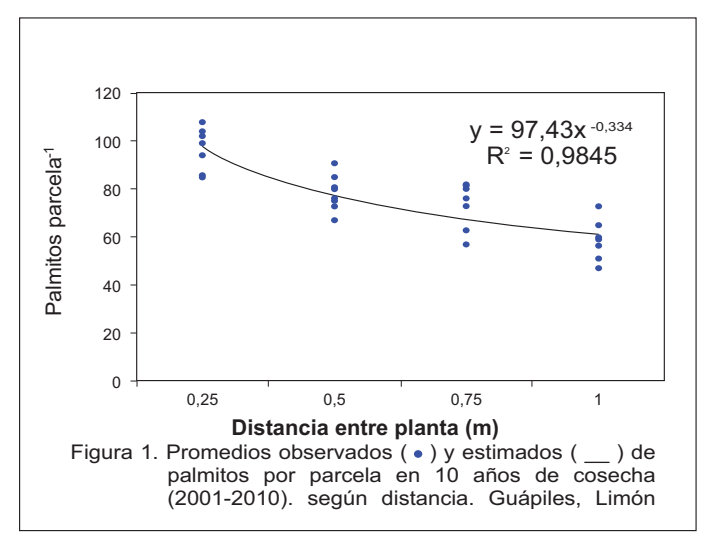

Hubo diferencias entre distancia $(p<0,01)$ en casi todos los años de producción excepto en el $2010(p=0,13)$. La relación entre distancias de siembra con respecto a la producción de palmitos por hectárea, durante diez años es consecuente con el promedio o sea que disminuyeron conforme aumentó la distancia entre plantas (disminuyó la densidad). La producción promedio más alta ( 15055 palmitos ha $^{-1}$ ) se obtuvo con la distancia $0,25 \mathrm{~m}$ entre plantas, mientras que la más baja (9273) con $1 \mathrm{~m}$ entre plantas (Cuadro 2).

En las altas densidades (distancias 0,25 y $0,50 \mathrm{~m}$ ), los rendimientos son más altos al inicio y van decreciendo con los años probablemente por la densidad y la competencia de hijos, mientras que las bajas densidades (distancias 0,75 y $1,00 \mathrm{~m}$ ) se observan rendimientos más estables en el tiempo, quizá por menos competencia (Cuadro 2). Una ventaja de la alta densidad (Mora 1999) es obtener altos 
rendimientos en los primeros meses o años de producción, lo cual justificaría la mayor inversión inicial. En general para todas las distancias hubo períodos de baja producción como el observado entre 2003-2005 el cual pudo ser afectado por la incidencia de bacteriosis (Pantoea stewarti y Fusarium sp.) (Mora et al. 2005, Bogantes 2007).

Cuadro 2. Rendimiento (unidades) de palmito ha-1, según distancia en diez años de cosecha (2001-2010). Guápiles, Limón, Costa Rica. 2011.

\begin{tabular}{|c|cccc|}
\hline \multirow{2}{*}{ Año } & \multicolumn{4}{|c|}{ Distancia entre planta(m) } \\
\cline { 2 - 5 } 2001 & 0,25 & 0,5 & 0,75 & 1 \\
2002 & 21578 & 14438 & 11044 & 8953 \\
2003 & 17047 & 14422 & 11893 & 11281 \\
2004 & 12047 & 10609 & 9272 & 9125 \\
2005 & 13078 & 9922 & 9242 & 7859 \\
2006 & 13203 & 11172 & 9908 & 8219 \\
2007 & 13719 & 11016 & 10151 & 8219 \\
2008 & 18906 & 15516 & 13044 & 10813 \\
2009 & 15609 & 13266 & 11075 & 9188 \\
2010 & 14625 & 11484 & 11029 & 10250 \\
Promedio ha $^{-1}$ & 10734 & 9656 & 9090 & 8828 \\
Promedio parcela $^{-1}$ & $\mathbf{1 5 ~ 0 5 5 ~ a ~}$ & $\mathbf{1 2} \mathbf{1 5 0} \mathbf{~ b}$ & $\mathbf{1 0 ~ 5 7 5 ~ c}$ & $\mathbf{9 2 7 3} \mathbf{~ d}$ \\
\hline
\end{tabular}

Medias con diferente letra en la misma fila, difieren según Duncan $(P \leq 0,05)$.

\section{Rendimiento industrial}

En Costa Rica, el palmito que se vende a las plantas procesadoras es pagado por rendimiento, o sea, que a mayor peso de palmito foliar, mayor es el pago al productor. La referencia del rendimiento industrial es el número de palmitos requeridos por caja equivalente de $5,28 \mathrm{~kg}$.

El peso (fresco) unitario del palmito foliar $(p=0,61)$ y caulinar $(p=0,48)$ no fue diferente entre distancias de siembra. En todas las distancias, el rendimiento del palmito foliar, estuvo por debajo del parámetro deseado por Mora (2002). Lo anterior, se debe a que la cosecha o corte del palmito se hizo tipo "barrido" o sea sin considerar lo que se denomina "corte por candela", que consiste en cortar el palmito según el tamaño de la candela (hoja guía). En efecto, hay evidencia, en el caso de esta variedad Diamantes 10 sobre una correlación $(r=0,71)$ altamente significativa $(p=0,0001)$ entre apertura de la hoja guía y peso del palmito foliar (Arroyo y Mora 2002).

El peso por hectárea del palmito foliar, depende principalmente, del número de palmitos producidos; por lo tanto, el rendimiento en $\mathrm{kg}$ y en cajas estándar, aumentó con la mayor densidad. En ese sentido, se nota que la producción de cajas de palmito, obtenidos con la distancias de 0,25 y $0,75 \mathrm{~m}$ superan en 19 y $30 \%$, los rendimientos obtenidos cuando se sembró a $1 \mathrm{~m}$ entre planta (Cuadro 3).

En todas las distancias, el peso del palmito caulinar (cabeza), fue muy superior al 
parámetro ideal, basado en $379 \mathrm{~g}^{\text {palmito- }}{ }^{-1}$ (Mora 2002). Esto es muy importante y justifica la metodología para este análisis de rendimiento industrial, en la cual se decidió, cortar el palmito con $75 \mathrm{~cm}$ de largo y no como lo exige la industria $(55 \mathrm{~cm}$ de largo, con un máximo de $9 \mathrm{~cm}$ de palmito caulinar o cabeza), precisamente para documentar este mayor aprovechamiento que se le puede dar en la industria al palmito caulinar de una variedad como la Diamantes 10 , si se corta más largo y con más "cabeza".
Por otra parte, la mayor altura que se obtuvo en las plantas sembradas a menor distancia (Cuadro 4), no tuvo un efecto directo en el número de trozos de palmito foliar pero sí en su peso, el cual bajó de 43,7 g en las plantas sembradas a $1,00 \mathrm{~m}$ hasta $37,2 \mathrm{~g}$ en la plantas a 0,25 m. Lo anterior, tiene importancia en el momento en que la industria prefiera un palmito más delgado para competir con el espárrago (Mora 1989).

Cuadro 3. Rendimiento industrial de palmito foliar (peso fresco), palmito caulinar (peso fresco) y cajas ha-1 (palmito foliar), según distancia de siembra. Guápiles, Limón, Costa Rica. 2011.

\begin{tabular}{|c|c|c|c|c|c|c|}
\hline $\begin{array}{c}\text { Distancia } \\
\text { planta } \\
(\mathrm{m})\end{array}$ & $\begin{array}{c}\text { Palmito } \\
\text { foliar } \\
\left(\mathrm{g} \mathrm{unidad}^{-1}\right)\end{array}$ & $\begin{array}{c}\text { Palmito } \\
\text { caulinar } \\
\left(\text { (gunidad }^{-1}\right)\end{array}$ & $\begin{array}{c}\text { Palmito foliar } \\
\left(\mathrm{kg} \mathrm{parcela}^{-1}\right)\end{array}$ & $\begin{array}{c}\text { Palmito } \\
\text { foliar } \\
\left(\mathrm{kg} \mathrm{ha}^{-1}\right)\end{array}$ & $\begin{array}{c}\text { Palmito foliar } \\
\left(\text { cajas ha }^{-1}\right)^{*}\end{array}$ & $\begin{array}{c}\text { Diferencia } \\
(\%)\end{array}$ \\
\hline 0,25 & 71,50 n. s. & 460 n. s. & 6,89 & $1076 \mathrm{a}$ & 204 & 19 \\
0,50 & 97,58 & 479 & 7,59 & $1186 \mathrm{~b}$ & 224 & 30 \\
0,75 & 82,50 & 463 & 5,76 & $872 \mathrm{~d}$ & 165 & -4 \\
1,00 & 98,33 & 406 & 5,83 & $911 \mathrm{c}$ & 172 & 0 \\
\hline
\end{tabular}

* Peso de caja equivalente $5,28 \mathrm{~kg}$ (solo de palmito foliar). Calculado con el promedio de palmitos de los 10 años. Medias con diferente letra en la misma columna, difieren según Duncan $(p \leq 0,05)$. n. $s .=$ sin diferencias entre distancias.

\section{Aporte y extracción de biomasa}

El palmito se corta cuando los tallos (unidades de palmito) tienen al menos $9 \mathrm{~cm}$ de grosor, medidos en la base a $10 \mathrm{~cm}$ del suelo. Las plantas sembradas a 0,25 m entre sí fueron más altas $(p=0,03)$ y se cortaron con su tallo más delgado $(p=0,02)$. Esto se puede atribuir a la competencia por la alta densidad, ya que, estas dos variables (altura y grosor) correlacionaron $\left(r^{2}=-0,93\right.$ y $\left.p=0,06\right)$. No obstante, estas características no incidieron en el peso total de la planta $(p=0,63)$ ni en peso del palmito $(p=0,45)$.

No hubo diferencias entre distancias $(p=0,97)$ en el porcentaje de extracción de biomasa (peso fresco) por unidad de palmito, el cual anduvo alrededor del $20 \%$. Con estos datos, es claro que por cada $100 \mathrm{~kg}$ de biomasa fresca cortados, se incorporan al sistema (suelo) $80 \mathrm{~kg}$ y aún más obvio que a mayor producción por hectárea mayor es la cantidad de biomasa que se incorpora al sistema (Cuadro 4). En ese sentido, Molina et al. (2002) calcularon que con 11214 palmitos $\mathrm{ha}^{-1}$ se tiene una cantidad de $13 \mathrm{t}$ de materia seca, de la cual, solo el $11 \%$ se remueve con el palmito; por otra parte, Herrera (1989) estimó una remoción del $8,5 \%$ de materia seca por cada palmito extraído de la plantación. 
Cuadro 4. Promedios de altura, peso total de la planta y del palmito a una cáscara. Grosor del tallo, extracción y aporte de biomasa (peso fresco) a cosecha, según distancia de siembra. Guápiles, Limón, Costa Rica. 2001-2011.

\begin{tabular}{|c|c|c|c|c|c|c|}
\hline $\begin{array}{c}\text { Distancia } \\
(\mathrm{m})\end{array}$ & $\begin{array}{c}\text { Altura } \\
\text { planta }(\mathrm{cm})\end{array}$ & $\begin{array}{c}\text { Grosor del } \\
\text { tallo }(\mathrm{cm})\end{array}$ & $\begin{array}{c}\text { Peso de la } \\
\text { planta }(\mathrm{kg})\end{array}$ & $\begin{array}{c}\text { Peso del } \\
\text { palmito }(\mathrm{kg})^{*}\end{array}$ & $\begin{array}{c}\text { Extracción } \\
(\%)\end{array}$ & $\begin{array}{c}\text { Biomasa } \\
(\mathrm{kg}) \text { ha }^{-1 * *}\end{array}$ \\
\hline 0,25 & $161 \mathrm{a}$ & $9,08 \mathrm{a}$ & 7,02 n.s. & 1,38 n.s. & 19,67 n.s. & 84910 \\
0,50 & $153 \mathrm{ab}$ & $9,36 \mathrm{~b}$ & 6,56 & 1,30 & 20,00 & 63909 \\
0,75 & $145 \mathrm{ab}$ & $9,45 \mathrm{~b}$ & 6,43 & 1,25 & 19,44 & 54778 \\
1,00 & $139 \mathrm{~b}$ & $9,49 \mathrm{~b}$ & 6,37 & 1,25 & 19,62 & 47478 \\
\hline
\end{tabular}

* Peso fresco a una cáscara **Peso fresco. Medias con diferente letra en la misma columna, difieren según Duncan $(p \leq 0,05)$. n. $s .=$ sin diferencias entre distancia.

\section{Características de la cepa}

En este estudio se hizo resiembra antes de las ocho semanas posterior a la siembra. Por lo que resulta importante observar la sobrevivencia de las mismas en el tiempo. Con nueve años de edad el mayor porcentaje de sobrevivencia de cepas se obtuvo con la distancia $1 \mathrm{~m}$ entre planta y fue descendiendo el porcentaje hasta $53 \%$ en las parcelas sembradas a $0,25 \mathrm{~m}$ (Cuadro 5). No obstante, es importante comentar, que el espacio lo cubrieron las cepas que quedaron, sobre todo, en la alta densidad $(0,25 \mathrm{~m})$, con lo cual, se da un equilibrio y un diseño de plantación que se comentará más adelante.

Cuadro 5. Número de cepas en cada distancia de siembra al inicio (2000) y a los nueve años del estudio (2009). Guápiles, Limón, Costa Rica. 2001-2011.

\begin{tabular}{|c|c|c|c|}
\hline $\begin{array}{c}\text { Distancia entre plantas } \\
(\mathrm{m})\end{array}$ & \multicolumn{2}{|c|}{ Número de cepas parcela- ${ }^{-1}$} & \% de sobrevivencia \\
\hline & $\begin{array}{c}\text { Inicial (marzo } \\
2000)\end{array}$ & mayo del 2009 & 2009 \\
\hline 0,25 & 128 & 68,40 & 53 \\
\hline 0,50 & 64 & 45,30 & 71 \\
\hline 0,75 & 44 & 34,20 & 78 \\
\hline 1,00 & 32 & 25,90 & 81 \\
\hline
\end{tabular}

El largo $(p<0,001)$, el ancho $(p=0,0001)$ y la altura $(p=0,0001)$ de las cepas, nueve años después de sembradas las plantas, fue diferente entre distancias de siembra (Cuadro 6). Esto afectó la forma de cada cepa, tal y como se aprecia, en las imágenes de la Figura 2. La cepa fue más larga, más ancha y más alta conforme aumentó la distancia entre planta; eso era lo esperado, considerando el espaciamiento entre ellas (sembradas originalmente a un metro entre sí). 
Cuadro 6. Largo, ancho y altura de las cepas en cada distancia de siembra a los nueve años del estudio (2009). Guápiles, Limón, Costa Rica. 2001-2011.

\begin{tabular}{|c|c|c|c|}
\hline $\begin{array}{c}\text { Distancia entre plantas } \\
(\mathrm{m})\end{array}$ & Largo cepa $(\mathrm{cm})$ & Ancho de cepa $(\mathrm{cm})$ & Altura de cepa $(\mathrm{cm})$ \\
\hline 0,25 & $50 \mathrm{~cm}($ surco $)$ & $27,71 \mathrm{c}$ & $5,83 \mathrm{~d}$ \\
\hline 0,50 & $38,16 \mathrm{a}$ & $30,25 \mathrm{bc}$ & $11,17 \mathrm{c}$ \\
\hline 0,75 & $43,50 \mathrm{~b}$ & $32,54 \mathrm{~b}$ & $14,79 \mathrm{~b}$ \\
\hline 1,00 & $55,12 \mathrm{c}$ & $42,75 \mathrm{a}$ & $19,04 \mathrm{a}$ \\
\hline
\end{tabular}

Medias con diferente letra en la misma columna, difieren según Duncan $(P \leq 0,05)$.

El crecimiento de la cepa en el tiempo, es importante porque tiene que ver con el equilibrio que se da cuando otras cepas cubren el espacio de las que se mueren tal y como se analizó anteriormente. En el caso de las plantas sembradas 0,25 m entre sí, a los nueve años, la cepa ya se había convertido casi que en un surco (Figura 2) incluso, no se pudo medir la longitud individual y se referenció solo el ancho y su altura en un espacio predefinido de $50 \mathrm{~cm}$ de largo (Cuadro 6). En relación con cepas altas, lo importante es eliminar los hijos encimados o sea los que crecen en la parte alta o sobre la cepa y nunca tocan el suelo para que crezcan los hijos periféricos que son los que agregan raíz y rejuvenecen el sistema radical (Mora et al. 1999).
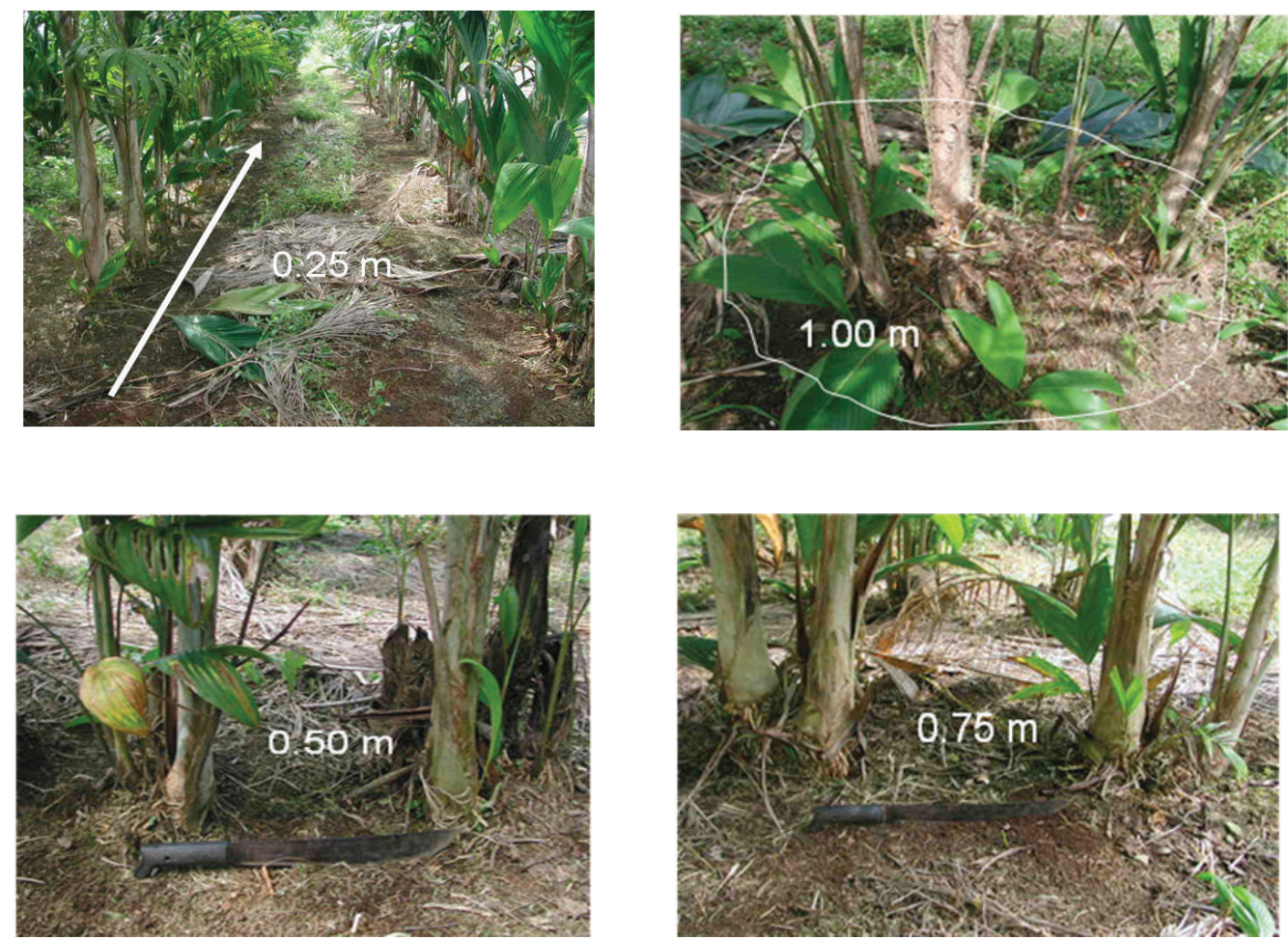

Figura 2. Cepas de palmito con diferente distancia (original) de siembra entre sí y con nueve años de edad. Guápiles, Limón, Costa Rica. 2011. 
Con respecto al número de estípites (hijos por cepa) a los nueve años de edad, hubo diferencias entre distancias $(p<0,0001)$. El número de hijos disminuyó en forma curvilínea conforme disminuyó la distancia entre plantas (aumento de densidad), estabilizándose entre 6 a 8 hijos por cepa cuando la distancia fue
0,25 m entre plantas (mayor densidad) (Figura 3 ). La producción de estípites en los materiales sin espinas es más baja que en los que tienen espinas, situación que no limita la producción, sobre todo, a altas densidades (más de 10000 $\mathrm{pl} \mathrm{ha-1)}$ en las que se requieren dos o tres hijos por cepa (Mora 2002).

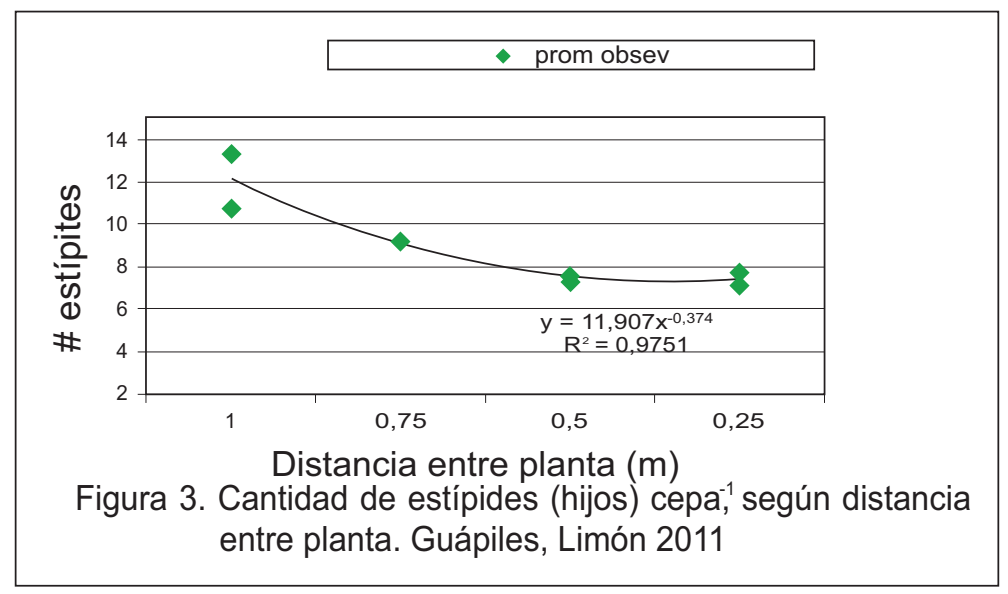

La altura de los estípites, no varió entre distancias $(p=0,70)$ y estuvo entre 71 y $77 \mathrm{~cm}$, en la medición que se hizo en el 2009. Sí hubo diferencia en el grosor de esos hijos $(p=0,004)$ y que coincide con lo encontrado cuando se midió el grosor del tallo a la cosecha. El grosor aumenta conforme hay más distancia entre plantas (menos densidad) (Figura 4). Es evidente que ese comportamiento se da en respuesta a la competencia por espacio en el tiempo, contrario a los primeros seis meses en los cuales hubo buen espaciamiento entre plantas y los tallos tenían similar grosor (Bogantes et al. 2004).

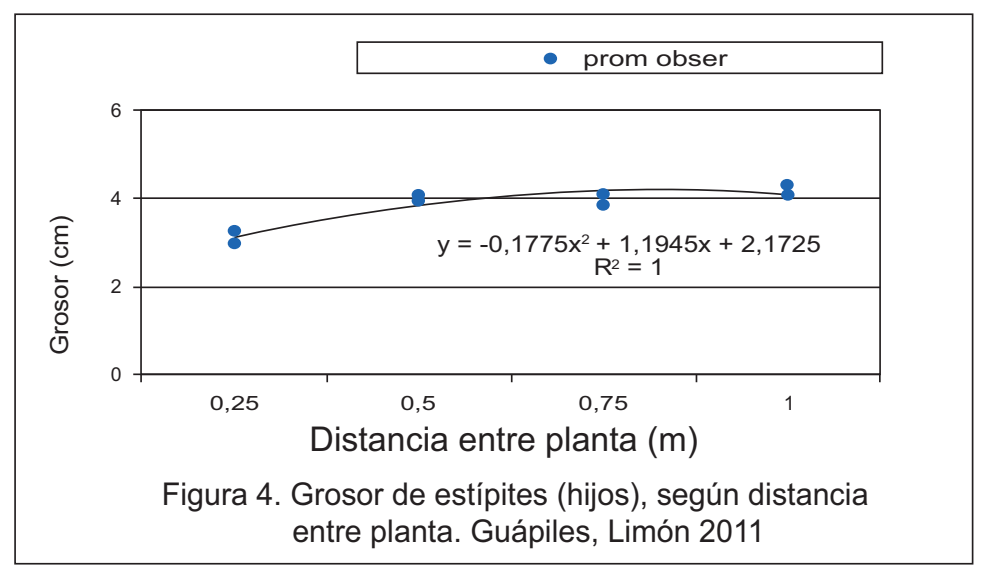




\section{Cobertura de arvenses (malezas)}

El porcentaje de arvenses presentes tanto en mayo, como en octubre del 2011 varió $(p=0,002)$ según la distancia de siembra (Figura 5 y Cuadro 7). Como se esperaba, la cobertura aumentó conforme al aumento en la distancia entre plantas. Se observa una tendencia asintótica que tiende a estabilizarse en la distancia de un metro entre planta (Figura 5, Cuadro 7). Este mismo comportamiento pero con mayor cobertura (60 hasta $75 \%$ ) se observó en los centros de estas parcelas a los nueve meses después de la siembra (Bogantes y Agüero 2003).

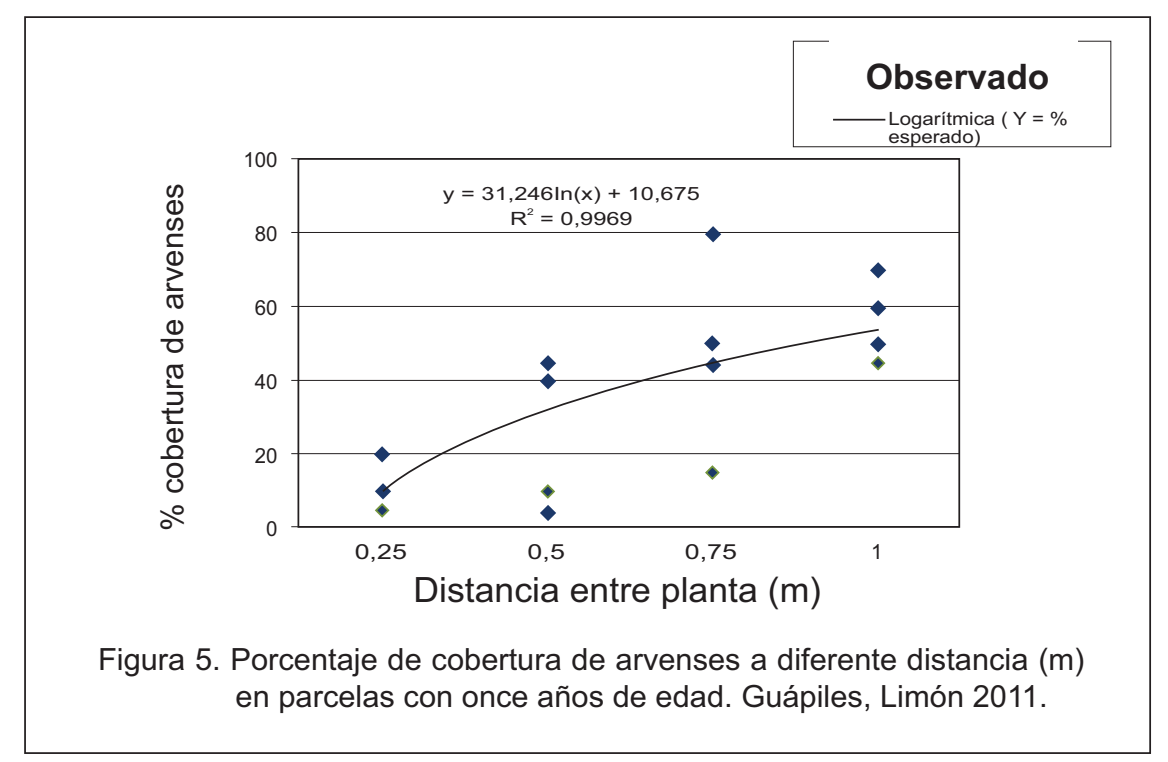

En general, se identificaron un total de 23 especies de arvenses (Cuadro 7) a los once años de sembrado el experimento (mayo del 2011). Esa cantidad, es muy similar a las 24 especies identificadas a los 14 meses de edad (Bogantes y Agüero 2003). No obstante, si se comparan las épocas, la diversidad es otra, ya que un total de 10 especies actuales no estaban a los 14 meses de edad de la plantación, mientras que, aproximadamente 12 especies que prevalecían a los 14 meses, no están en la actualidad. Más interesante aún, son los cambios en las especies dominantes, ya que, a los 14 meses de edad Paspalum fasciculatum y Ageratun conyzoides, eran las especies de arvenses que dominaban en el sistema (Bogantes y Agüero 2003) pero en la actualidad, la especie dominante es Spermacoce laveis (Cuadro 7), una especie difícil de controlar con el herbicida glifosato $y$ que se ha diseminado en varios cultivos (Bogantes et al. 2010). Es muy probable que los cambios en la entrada de radiación lumínica, la humedad, los residuos de la cosecha depositada, así como, la aplicación de herbicida hayan contribuido como factores de modificación y selección, relacionados con la prevalencia o ausencia de especies en este período (11 años). 
Cuadro 7. Especies de malezas y sus promedios de cobertura en parcelas de palmito de pejibaye con diferentes distancias de siembra y con once años de edad.Pococí, Limón. Costa Rica. 2011.

\begin{tabular}{|l|c|c|c|c|c|}
\hline \multirow{2}{*}{ Especie } & \multirow{2}{*}{ Familia } & \multicolumn{5}{c|}{ Cobertura (\%) por distancia de siembra. } \\
\cline { 3 - 6 } & & $0,25 \mathrm{~m}$ & $0,50 \mathrm{~m}$ & $0,75 \mathrm{~m}$ & $1,00 \mathrm{~m}$ \\
\hline Alternanthera sessilis (L.) & Amaranthaceae & 0 & 0 & 0,62 & 0 \\
\hline Colocasia esculenta (L.) & Araceae & 0 & 0 & 0 & 2,5 \\
\hline Ageratum conyzoides (L.) & Asteraceae & 0 & 0 & 0 & 0,62 \\
\hline Emilia fosbergui (N.) & Asteraceae & 0,62 & 0 & 0 & 0 \\
\hline Vernonia patens (K.) & Asteraceae & 0 & 0,38 & 0,62 & 0 \\
\hline Rottboellia exaltata (L.) & Poaceae & 1,25 & 0,62 & 0,12 & 0 \\
\hline Panicum trichoides (S.) & Poaceae & 0,25 & 0,62 & 0,88 & 1,25 \\
\hline Paspalum paniculatum (L) & Poaceae & 0 & 0 & 3,12 & 20,25 \\
\hline Eleusine indica (L.) & Poaceae & 0 & 0,38 & 0 & 1,25 \\
\hline Drimaria cordata (L.) & Caryophyllaceae & 1,43 & 0,25 & 3,75 & 3,75 \\
\hline Conmelina diffusa (B.) & Conmelinaceae & 0 & 0 & 1,25 & 0 \\
\hline Cyperus spp & Cyperaceae & 1,25 & 6,25 & 6,62 & 3,75 \\
\hline Scleria pterota (P) & Cyperaceae & 0 & 1,88 & 2,12 & 1,88 \\
\hline Acalypha alopecuroides (J) & Euphorbiaceae & 0,88 & 0,25 & 1,50 & 1,50 \\
\hline Phyllantus niruri (L.) & Euphorbiaceae & 2 & 0,12 & 0,38 & 1,62 \\
\hline (Pteridium sp) & Hypolypodiaceae & 0 & 0,25 & 0,38 & 0 \\
\hline Sida acuta (B.) & Malvaceae & 0,12 & 0 & 0,25 & 0 \\
\hline Clidemia hirta (L.) & Melastomaceae & 0 & 0 & 0,25 & 0,38 \\
\hline Ludwigia decurrens (W.) & Onagraceae & 0 & 1,12 & 0 & 1,25 \\
\hline Peperomia pellucida (L.) & Piperaceae & 4,88 & 0,88 & 0,25 & 0,88 \\
\hline Spermacoce lavéis (L.) & Rubiaceae & 21,25 & 39,75 & 28 & 25,38 \\
\hline Lindernia sp & Scrophulariaceae & 0 & 0,75 & 0 & 0,25 \\
\hline Cissus verticillata (L.) & Vitaceae & 0,38 & 0 & 2,5 & 3,38 \\
\hline \multicolumn{2}{|c|}{ Cobertura total por distancia entre planta (\%) } & 34,31 & 53,50 & 52,62 & $69,86 \mathrm{n}=8$ \\
\hline & & & $\mathrm{n}=8$ & $\mathrm{n}=8$ & \\
\hline
\end{tabular}

\section{Estudios de suelo}

1) $\mathrm{pH}$ y Al intercambiable

En general el pH osciló entre 5,00 y 5,30 , según la distancia. El promedio antes de la siembra fue de 4,88 y aumentó a alrededor de 5,20 en el segundo muestreo, 13 meses después de la siembra (Cuadro 8).También los valores de Al fueron similares entre distancias $y$ en general parecidos a los resultados obtenidos al inicio y los 13 meses después de la siembra (Bogantes et al. 2006).

\section{2) Bases $\mathrm{Ca}, \mathrm{Mg}, \mathrm{K}$}

Las cantidades de $\mathrm{Ca}, \mathrm{Mg}$ y $\mathrm{K}$ entre distancias fueron parecidas con excepción del Ca en la parcela sembrada a 0,75 m entre planta (Cuadro 8). En general solo el $\mathrm{K}$ se ha mantenido estable desde el inicio. El Ca y el $\mathrm{Mg}$ descendieron sus niveles con respecto a 
los mostrados hace 10 años (al inicio y a los 13 mds) (Bogantes et al. 2006).

\section{3) P, Zn y Mn}

La cantidad de $\mathrm{P}, \mathrm{Zn}$ y $\mathrm{Mn}$ en este último muestreo, también fue similar entre distancias con excepción del Zn en la distancia a 0,75 m en la que bajó a 0,40 $\mathrm{mg} \mathrm{l}^{-1}$ (Cuadro 8). El $\mathrm{P}$ mantuvo los niveles que mostró al inicio del estudio, a pesar de que en el segundo muestreo había bajado. Las cantidades de $\mathrm{Zn}$ y de Mn sí descendieron en el segundo y aún más, en este último muestreo (Bogantes et al. 2006).

4) N y materia orgánica (M.O.)

El $\mathrm{N}$ en el suelo fue similar entre distancias (Cuadro 8) y en general mantuvo sus niveles con respecto al muestreo inicial (Bogantes et al. 2006). Las cantidades porcentuales de materia orgánica (MO) no variaron mucho entre distancias (Cuadro 8), pero en general, bajaron como en un $1,5 \%$ con respecto a los promedios iniciales (Bogantes et al. 2006).

La estabilidad de las mediciones de N-P-K en el suelo a lo largo del tiempo (11años) concuerda con lo descrito por Soto et al. (2002), quienes demuestran que hay una rápida liberación de estos nutrimentos (K-P-N) derivada de los residuos de cosecha y el orden de esa liberación en su estudio fue $\mathrm{N}=\mathrm{K}>\mathrm{P}>\mathrm{Mg}>\mathrm{Ca}$.

Soto et al. (2002) también estimaron que la cantidad de nutrimentos provenientes de los residuos de cosecha y potencialmente disponibles en base anual, oscila entre $93 \mathrm{y}$ $107 \mathrm{~kg} \mathrm{ha}^{-1}$ de N, 14 a $15 \mathrm{~kg} \mathrm{ha}^{-1}$ de P, 90 a 116 de K, 19-23 de Ca y 13-14 de Mg. En el caso particular del fósforo $(\mathrm{P})$, Boniche et al. (2008) determinaron que su adición con fertilizante, no afectó en forma importante el crecimiento de las plantas ni la producción de palmitos y recomiendan aplicarlo al suelo en plantaciones establecidas de 10000 plantas ha- ${ }^{-1}$ con una dosis de mantenimiento máxima de $30 \mathrm{~kg} \mathrm{ha}^{-1}$ año-1 de $\mathrm{P}_{2} \mathrm{O}_{5}$.
Soto et al. (2002) estimaron que con un 19\% de los residuos originales que se incorporan al suelo cada 48 semanas, es posible que una plantación de palmito de 16 años se encuentre cerca del punto de equilibrio, refiriéndose al N, P, K, Mg y Ca. En este mismo sentido Molina et al. (2002) estimaron que el $16 \%$ del $\mathrm{P}$ y K, así como, el $13 \%$ del $\mathrm{Mg}$ y el $12 \%$ del Ca se exportan del campo con la cosecha del palmito a dos cáscaras. De los residuos que permanecen en el campo el follaje contiene la mayor parte de nutrimentos que oscila entre $59 \%$ para $\mathrm{K}$ y $\mathrm{P}$ y $74 \%$ para $\mathrm{N}$.

En este estudio y en el caso particular del $\mathrm{Mg}$ y de el $\mathrm{Ca}$, parece que las cantidades incorporadas con los desechos más la fertilización química aplicada, no fueron suficientes para mantener un equilibrio en el suelo, dado los bajos niveles mostrados al final del período. Igual atención se le debe poner al $\mathrm{Zn}$ y al $\mathrm{Mn}$, muy deficitarios, después de estos 11 años de producción. 
Cuadro 8. Valores* en suelo de $\mathrm{pH}, \mathrm{Al}$, bases $\left(\mathrm{cmol} \mathrm{I}^{-1}\right)$; P, Zn, Mn (mg l-1); M.O. y N (\%) según distancia de siembra y estrategia de control de malezas, en el segundo muestreo (13 mds), en pejibaye para palmito. Guápiles, Limón, Costa Rica. 2011.

\begin{tabular}{|c|c|c|c|c|c|c|c|c|c|c|}
\hline $\begin{array}{c}\text { Distancia } \\
(\mathrm{m})\end{array}$ & $\mathrm{pH}$ & $\mathrm{Al}$ & $\mathrm{Ca}$ & $\mathrm{Mg}$ & $\mathrm{K}$ & $\mathrm{P}$ & $\mathrm{Zn}$ & $\mathrm{Mn}$ & $\mathrm{M} . \mathrm{O}$. & $\mathrm{N}$ \\
\hline 0,25 & 5,00 & 0,35 & 2,00 & 0,60 & 0,41 & 5,00 & 0,70 & 4,00 & 3,59 & 0,15 \\
0,50 & 5,00 & 0,45 & 1,70 & 0,50 & 0,30 & 5,00 & 0,80 & 5,00 & 3,61 & 0,15 \\
0,75 & 5,30 & 0,30 & 4,10 & 0,90 & 0,27 & 4,00 & 0,40 & 5,00 & 4,19 & 0,21 \\
1,00 & 5,10 & 0,40 & 2,10 & 0,80 & 0,31 & 6,00 & 0,60 & 4,00 & 3,89 & 0,16 \\
\hline
\end{tabular}

*Valores reportados por el laboratorio de suelos del INTA-MAG

5) Microorganismos en el suelo

Las cantidades de UFC de hongos y bacterias, fueron muy bajas en las parcelas a $0,25 \mathrm{~m}$ y fueron aumentando conforme aumentó la distancia. Todo lo contrario, las cantidades de UFC de actinos en el suelo de las parcelas a $0,25 \mathrm{~m}$, fueron mucho más altas que en las otras tres distancias (Cuadro 9). En general, las UFC de hongos bajaron con respecto al segundo muestreo hecho 13 mds, pero fueron similares con las del inicio del estudio (Bogantes et al. 2006).

Los actinos, bajaron mucho sus poblaciones con respecto al primer muestreo (con excepción de la parcela a 0,25 ). Solo en el segundo muestreo $13 \mathrm{mds}$ esas poblaciones fueron muy superiores al muestreo inicial. Coincidimos con Ramírez (1996) en que las prácticas de manejo como las de este estudio, relacionadas con densidades, la cosecha y la deshija podrían afectar la actividad de los microorganismos de una manera directa, al alterar los parámetros físicos y químicos, tales como penetración de radiación y temperatura del suelo, humedad, aireación, estado de oxireducción, contenido y composición de gases del espacio poroso y accesibilidad a sustratos. También la actividad microbiana depende mucho más de la disponibilidad de carbono fácilmente accesible que es utilizado como fuente de energía (Espinoza 1996) y que en nuestro caso está en función de los residuos de cosecha y podrían variar con la densidad.

Cuadro 9. Promedio de UFC de hongos, bacterias y actinos según la distancia y estrategia de control de malezas en palmito al final del estudio. Guápiles, Limón, Costa Rica. 2011.

\begin{tabular}{|c|c|c|c|}
\hline $\begin{array}{c}\text { Distancia } \\
(\mathrm{m})\end{array}$ & $\begin{array}{c}\text { Hongos } \\
\mathrm{UFC}^{*} 10 \mathrm{e}^{4}\end{array}$ & $\begin{array}{c}\text { Bacterias } \\
\text { UFC } 10 \mathrm{e}^{5}\end{array}$ & $\begin{array}{c}\text { Actinos } \\
\mathrm{UFC}^{*} 10 \mathrm{e}^{5}\end{array}$ \\
\hline 0,25 & 1,46 & 43,75 & 29,17 \\
0,50 & 10,42 & 125,00 & 1,88 \\
0,75 & 13,04 & 130,43 & 0,87 \\
1,00 & 21,74 & 97,83 & 2,17 \\
\hline
\end{tabular}

*Valores reportados por el laboratorio de Fitoprotección del INTA-MAG.

La descripción de los hongos que crecieron en medio de cultivo (jugos vegetales V8) correspondió a Phytophthora sp, Fusarium $\mathrm{sp}$, Geotrichum sp, Mucor sp, Choanephora sp, Trichoderma sp. presentes en el suelo de las parcelas con la distancia a 0,25 m entre planta; Phytophthora sp, Choanephora $\mathrm{sp}$, Trichoderma sp. en las parcelas con la distancia a 0,50 m; Phytophthora sp, Fusarium $\mathrm{sp}$, Geotrichum sp, Mucor sp, Blakeslea sp, 
Trichoderma sp. en la distancia a 0,75 m y Phytophthora sp, Fusarium sp, Mucor sp, Trichoderma sp. en las parcelas con plantas a $1 \mathrm{~m}$. En el caso de Phytophthora, es un hongo patógeno asociado con pudrición del cogollo en pejibaye (Vargas 1999). Fusarium, también es un hongo patógeno de follaje de palmito, asociado con "vena corchosa" (Vargas 1999) y relacionado con la bacteriosis del palmito (Mora et al. 2005). Los otros hongos son no patogénicos al palmito e incluso algunos son saprófitos (Vargas 2011²).

\section{6) Lombrices en el suelo}

El número de lombrices por muestra de 16 litros de suelo, varió entre distancias $(P=0,005)$. La cantidad de las lombrices fue superior en el suelo de las parcelas a 0,25 $\mathrm{m}$ y disminuyó en forma curvilínea conforme aumentó la distancia entre plantas (Figura 6). Habría que estudiar más en detalle, estas diferencias de lombrices entre las densidades y su relación con el microambiente, propiciado por la densidad de las plantas y sus raíces, los residuos de cosecha, las especies de malezas y su cobertura. Las lombrices son anélidos pobladores del suelo y en alguna medida son parámetro de la salud del suelo. En banano, Agüero et al. (2002), atribuyen a la morfología de las malezas presentes (parte aérea y raíz) un rol importante en la conservación de la humedad del suelo y por ende en la cantidad de lombrices presentes o ausentes bajo cada especie. Se podría atribuir a la materia orgánica, un papel importante en las poblaciones de lombrices; sin embargo, Boschini et al. (2009) estimaron el peso vivo de las lombrices por unidad de área y lo correlacionaron con la materia orgánica incinerada $(r=0,27)$ y con la materia orgánica titulable $(r=0,08)$ y concluyeron, que esos valores de correlación entre el contenido de materia orgánica existente en el suelo y la población de lombrices, indican poca relación de causa-efecto entre ambas variables.

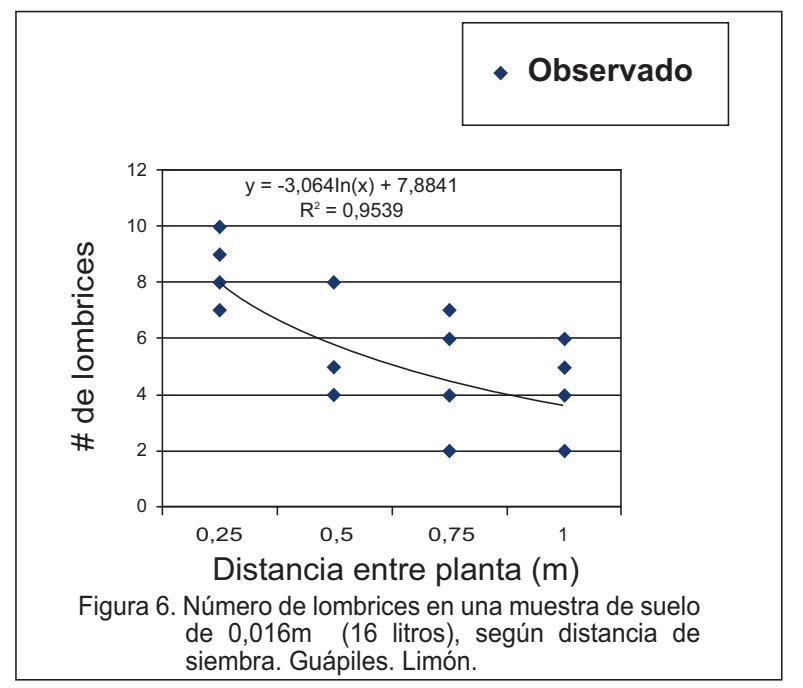

En términos generales la producción de palmitos fue superior en la distancia $0,25 \mathrm{~m}$ y descendió conforme aumentó la distancia. Es claro, que la variedad Diamantes 10 , sin espinas, puede dar un mejor aprovechamiento del palmito caulinar en la industria si se corta más largo (más de $55 \mathrm{~cm}$ de longitud y con más de $9 \mathrm{~cm}$ de palmito caulinar). A mayor densidad de plantas hay mayor aporte de biomasa al sistema e independiente de la distancia de siembra por cada $100 \mathrm{~kg}$ de biomasa fresca cortados, $80 \mathrm{~kg}$ se incorporan

\footnotetext{
${ }^{2}$ Vargas L. 2011. Relaciones entre hongos identificados en suelo de parcelas de palmito. Laboratorio de Fitoprotección. INTA San José, C.R. (comunicación personal).
} 
al sistema (suelo) y $20 \mathrm{~kg}$ se van en el palmito extraído. En las parcelas con las plantas sembradas a 0,25 m entre sí, la cepa ya se había convertido casi que en un surco a los nueve años de edad. Se identificaron un total de 23 especies de arvenses, después de once años de sembrado el experimento y se evidenciaron cambios en la diversidad de las especies dominantes, comparando diferentes épocas de muestreo. Se notó estabilidad en las cantidades N-P-K en el suelo obtenidas al final del estudio, comparado con información de once años atrás.

Con base en los resultados de este estudio y las referencias de otros relacionados también con el palmito de pejibaye sin espinas, cultivar Diamantes 10, es importante que se considere esta variedad en los futuros proyectos nacionales de ampliación, renovación o resiembras de plantaciones de palmito.

Agradecimiento: A los miembros de la Fundación FITTACORI por el apoyo económico en las diferentes etapas de esta investigación.

\section{LITERATURA CITADA}

Agüero, R.; Rojas, S.; Pérez, L. 2002. Poblaciones de lombrices bajo seis estrategias de manejo de malezas en una plantación de banano. Agronomía Mesoamericana 13(1):25-29.

Arroyo, C.; Mora, U, J. 2002. Producción comparativa de palmito entre cuatro variedades de pejibaye (Bactris gasipaes K.). Agronomía Mesoamericana. 13 (2):135-140.

Arroyo, C.; Mora, U, J. 2002. Relación entre el desarrollo de la hoja guía y el peso del palmito foliar en pejibaye (Bactris gasipaes KUNTH). Agronomía Mesoamericana 14(2):157-164.

Bogantes, A.; Agüero, R. 2003. Dinámica y control de malezas en pejibaye para palmito (Bactris gasipaes K). Agronomía Mesoamericana. 14 (1): 41-49
Bogantes, A.; Agüero, R.; Mora, J. 2004. Palmito de pejibaye (Bactris gasipaes): Distancias de siembra y manejo de malezas. Agronomía Mesoamericana. 15 (2):185-192.

Bogantes, A.; Agüero, R.; Mora, J.; Vargas, M. 2006. Distancias de siembra y manejo de malezas en pejibaye (Bactris gasipaes) para palmito: Efecto en el suelo y artrópodos. Agronomía Mesoamericana. 17(1):25-33.

Bogantes, A. 2007. Diferentes técnicas de manejo de pejibaye (Bactris gasipaes) para palmito y su efecto en la producción, incidencia de la "bacteriosis" y del "picudo". Revista Alcances Tecnológicos. 5(1):9-18.

Bogantes, A.; Hernández, M.; Mora, E. 2010. Herbicidas para el control de Spermacoce tenuior en papaya (Carica papaya) Agronomía Mesoamericana. 21 (1): 185-192.

Bogantes, A. 2010. Manual de Recomendaciones técnicas en el cultivo de de palmito de pejibaye (Bactris gasipaes K.). INTA. San José, Costa Rica. 15 p.

Boniche, J.; Alvarado, A.; Molina, E.; Ares, A.; Smyth, J .2008 Respuesta del pejibaye para palmito a la fertilización con fósforo en la zona Norte de Costa Rica. Agronomía Costarricense 32(1):31-54.

Boschini, C.; Chacón, A.; Araya J. 2009. Población de lombrices (Oligochaeta: Annelida) en una finca con bovinos lecheros, en Costa Rica. Agronomía Mesoamericana 20(1):91-99.

Chalá, V. 1991. Evaluación de 8 densidades de siembra de Bactris gasipaes H.B.K. para producción de palmito en la región amazónica ecuatoriana. In IV Congreso internacional sobre Biología, Agronomía e Industrialización del Pijuayo. U.C.R. San José, Costa Rica. pp 255-265.

Chaimsohn, F. P.; Mora-Urpí, J.; Villalobos-R. E. 2007. Densidades de siembra arreglos 
espaciales y fertilización en pejibaye (Bactris gasipaes cv 'DIAMANTES-10') para palmito. Agronomía Mesaoamericana 18(2):205-220.

Espinoza, J. 1996. Relación entre la fertilización mineral, la materia orgánica y los microorganismos del suelo. In $\mathrm{X}$ Congreso Nacional Agronómico y de Recursos Naturales. San José, Costa Rica. EUNED. pp 119-128.

Herrera, W. 1989. Fertilización del pejibaye para palmito. Serie técnica. Pejibaye-UCR. San José, Costa Rica. Boletín Informativo 1(2):5-10.

López, P G.; López, P J. 1995. Introducción al Micro-SAS: Aplicación al análisis de experimentos agrícolas. Unidad de Informática y Bioestadística. CATIE, Turrialba, Costa Rica. $119 \mathrm{p}$.

Molina, E.; Alvarado, A.; Boniche, J.; Smyth, T. 2002. Acumulación de biomasa y nutrimentos en plantaciones de palmito en Guápiles, Costa Rica. Agronomía Costarricense 26(2):53-62

Mora, J. 1989. Densidades de siembra para producción de palmito. Universidad de Costa Rica. Serie técnica Pejibaye 1. (1):10-12.

1999. Morfología (cap 1). Variedades (cap 2). Prácticas agronómicas de la araña (cap 5). In: Palmito de pejibaye (Bactris gasipaes K.) su cultivo e industrialización. San José, Costa Rica. Editorial U.C.R. pp 32-114.

2002. Presente y futuro del palmito en Costa Rica. Análisis y comentario. Agronomía Costarricense 26(2):95-100.

Mora, U.; Sánchez, E.; Wang, A.; Uribe, L.; Pizarro, L.; Chaimsohn, P.; Vargas, L.; Bogantes, A.; Mexzón, R.; Arroyo, C. 2005. Combate de la "bacteriosis" del palmito de pejibaye. Folleto técnico, CONICIT-UCRINTA-PITTA PEJIBAYE. SIEDIN-UCR, Costa Rica. 22 p.

Ramírez, C. 1996. Efecto de las prácticas agrícolas sobre la microflora del suelo:
Oportunidades en la Fitoprotección. In: X Congreso Nacional Agronómico y de Recursos Naturales. San José, Costa Rica. EUNED. p 81.

SEPSA. (Secretaría Ejecutiva de Planificación Sectorial Agropecuaria, CR). 2006. Boletín Estadístico Agropecuario Área de Estudios Económicos e Información. Boletín 17. pag 22-69.

Soto, G.; Luna, P.; Wagger, M.; Smyth, T.; Alvarado, A. 2002. Descomposición de residuos de cosecha y liberación de nutrimentos en plantaciones de palmito en Costa Rica. Agronomía Costarricense. 26(2):43-51.

Vargas. A. 1994. Evaluación de 8 densidades de siembra en pejibaye para palmito (Bactris gasipaes k.) en el Atlántico de Costa Rica. CORBANA 19 (42):11-16.

2000. La palmera de pejibaye (Bactris gasipaes K) y su cultivo en Costa Rica para la obtención de palmito. CORBANA, San José, Costa Rica 67 p.

Vargas, E. 1999. Principales enfermedades del palmito de pejibaye. Malezas, enfermedades y plagas (cap 6). In: Palmito de pejibaye (Bactris gasipaes K.) su cultivo e industrialización. Editores J. Mora y J. Gainza. San José, Costa Rica. Editorial U.C.R. pp 133-137.

Zamora, C. 1984. Densidades de siembra de pejibaye para palmito con tallo simple y tallo doble. In: Sexto Informe de labores 19831984. ASBANA. p 75-80. 